\title{
Metastatic breast tumor due to nonfunctional parathyroid carcinoma
}

\author{
Naotaka Uchida $\cdot$ Kiyosuke Ishiguro • \\ Takako Suda $\cdot$ Yasushi Horie $\cdot$ Motonobu Nishimura
}

Received: 29 June 2011 / Accepted: 14 November 2011/Published online: 20 December 2011

(C) The Japan Society of Clinical Oncology 2011

\begin{abstract}
Nonfunctional parathyroid carcinoma is a very rare malignant disease; only 25 cases have been reported over the last 85 years. We present a patient with a nonfunctional parathyroid carcinoma metastasis to the breast and a review of the pertinent literature. A 71-year-old woman was seen for a self-discovered mass in her left breast. She had undergone surgery 6 years previously for nonfunctional parathyroid cancer. Mammography and ultrasonography of the breast revealed an oval, circumscribed mass. Fine-needle aspiration findings were suspicious for metastasis of parathyroid carcinoma. Serum calcium and intact parathyroid hormone levels were within normal limits. We performed a partial mammary gland resection that included the tumor. Pathological analysis of the resected tumor disclosed findings consistent with parathyroid carcinoma. The nonsecretory state of the tumor was supported by negative immunoreactivity for parathyroid hormone in the tissue and lack of clinical evidence of hyperparathyroidism. To the best of our knowledge, this is the first reported case of parathyroid carcinoma metastasis to the breast. Breast metastasis of parathyroid carcinoma should be included in the differential diagnosis for a patient with a past history of parathyroid carcinoma.
\end{abstract}

\footnotetext{
N. Uchida $(\bowtie) \cdot$ K. Ishiguro - T. Suda · M. Nishimura Division of Organ Regeneration Surgery, Department of Surgery, Faculty of Medicine, Tottori University, 36-1 Nishi-cho, Yonago, Tottori 683-8504, Japan e-mail: naotakau@grape.med.tottori-u.ac.jp

Y. Horie

Department of pathology, Faculty of Medicine,

Tottori University, 36-1 Nishi-cho, Yonago,

Tottori 683-8504, Japan
}

Keywords Nonfunctional parathyroid carcinoma . Metastasis to the breast

\section{Introduction}

Parathyroid carcinoma accounts for $6 \%$ of patients with primary hyperparathyroidism in Japan [1]. The management of parathyroid carcinoma is primarily surgical, with en bloc resection of the tumor and involved adjacent structures. Cervical recurrences and lung metastases are most commonly encountered, and metastases to bone, liver, or pancreas have also been reported [2-6]. The overall 5and 10-year survival rates have been reported as 85 and $49-77 \%$, respectively [7, 8]. Most deaths are related to hypercalcemia.

While functional parathyroid carcinoma is an uncommon tumor, nonfunctional parathyroid carcinoma is exceedingly rare, with 25 reported cases in the world literature [9-12]. The presence of a neck mass is the common presenting symptom for nonfunctional parathyroid carcinoma, because the carcinoma is usually detected at an advanced stage because of the lack of hypercalcemiaassociated symptoms. Operative resection is the only effective treatment modality, but more extensive surgery is often necessary, because of the higher frequency of local invasion or metastasis at diagnosis than seen for functional parathyroid carcinomas [12]. Presentation in the late stages and ineffective adjuvant therapies result in dismal outcomes. Patients dying from the disease eventually succumb to systemic tumor burden.

Previously, Nakamura et al. [10] reported this patient as a case of nonfunctional parathyroid carcinoma. In the present report, we describe a metastasis to her breast that was discovered 6 years after the initial surgery. To our 

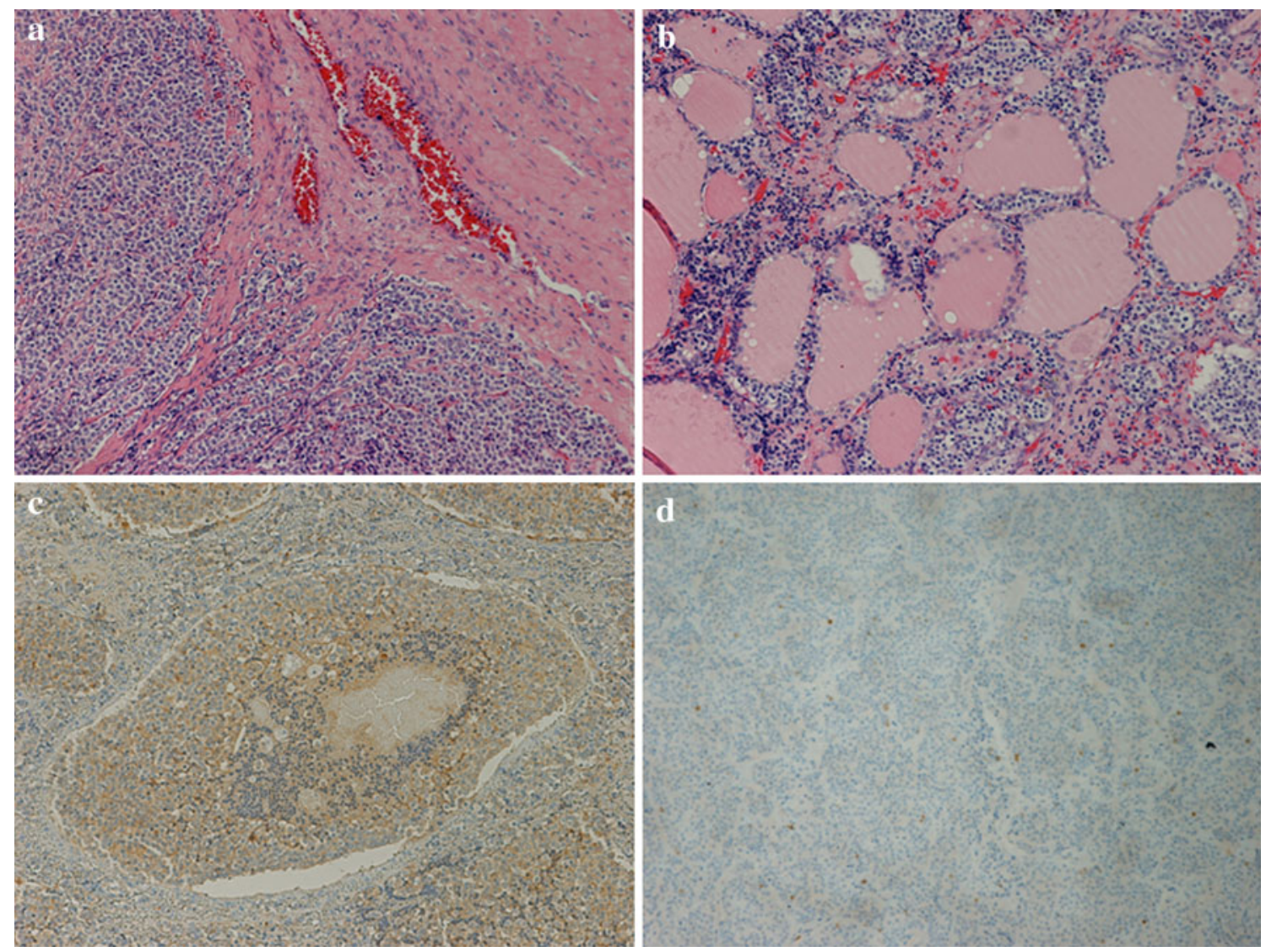

Fig. 1 Histological sections of the primary parathyroid carcinoma. a Fibrous bands and focal tumor cells stained with hematoxylin and eosin $(H \& E)(\times 40)$. b Tumor cells invading the thyroid (H\&E stain

knowledge, this is the first report in the world literature of parathyroid cancer that metastasized to the breast.

\section{Case report}

A 71-year-old woman presented with a mass in her left breast that she discovered herself. She had undergone initial surgery at our hospital in December 2004 performed by an otolaryngologist for a nonfunctional parathyroid cancer [10]. The surgical procedure consisted of resection of the tumor plus the left lobe of the thyroid gland, and lymph node dissections of the left neck and superior mediastinum. Histopathological examination of the primary tumor revealed dense fibrous band separating lobules of tumor cells, mitotic figures, necrosis, capsular invasion, and invasion of thyroid tissue (Fig. 1a, b). Immunoperoxidase staining of the primary tumor for carcinoembryonic antigen (CEA), thyroglobulin, S-100 protein, epithelial membrane antigen (EMA), calcitonin, carbohydrate antigen 19-9 (CA19-9), and parathyroid hormone (PTH) was negative, $\times 40)$. c Tumor cell cytoplasm is clearly stained with chromogranin A $(\times 100)$. d Ki-67 reactivity of primary tumor $(\times 100)$

but strongly reactive for neuron-specific enolase (NSE) and chromogranin A (Fig. 1c). The Ki-67 labeling index of the primary tumor was $7.9 \%$ (Fig. 1d). Because there were 12 lymph nodes positive for metastases, postoperative radiotherapy (RT) (50 Gy in 25 treatments) was performed. The patient was then followed as an outpatient. Four years after her initial treatment, she had a recurrence in a superior mediastinal lymph node and underwent surgery consisting of resection of the superior mediastinal lymph node and dissection of the left supraclavicular lymph nodes. Six years after her initial surgery, she suddenly developed left hypoglossal nerve palsy caused by metastasis to the occipital bone around the left hypoglossal canal. She was to undergo RT of the affected area. Six years and 1 month after her initial surgery, she noticed the left breast mass and was referred to us.

Physical examination revealed a $1.5-\mathrm{cm}$ firm, circumscribed mass in the superior lateral region $3 \mathrm{~cm}$ from the nipple in the left breast. On mammography, mediolateral oblique and craniocaudal views revealed an oval, circumscribed mass of higher density than fibroglandular breast 

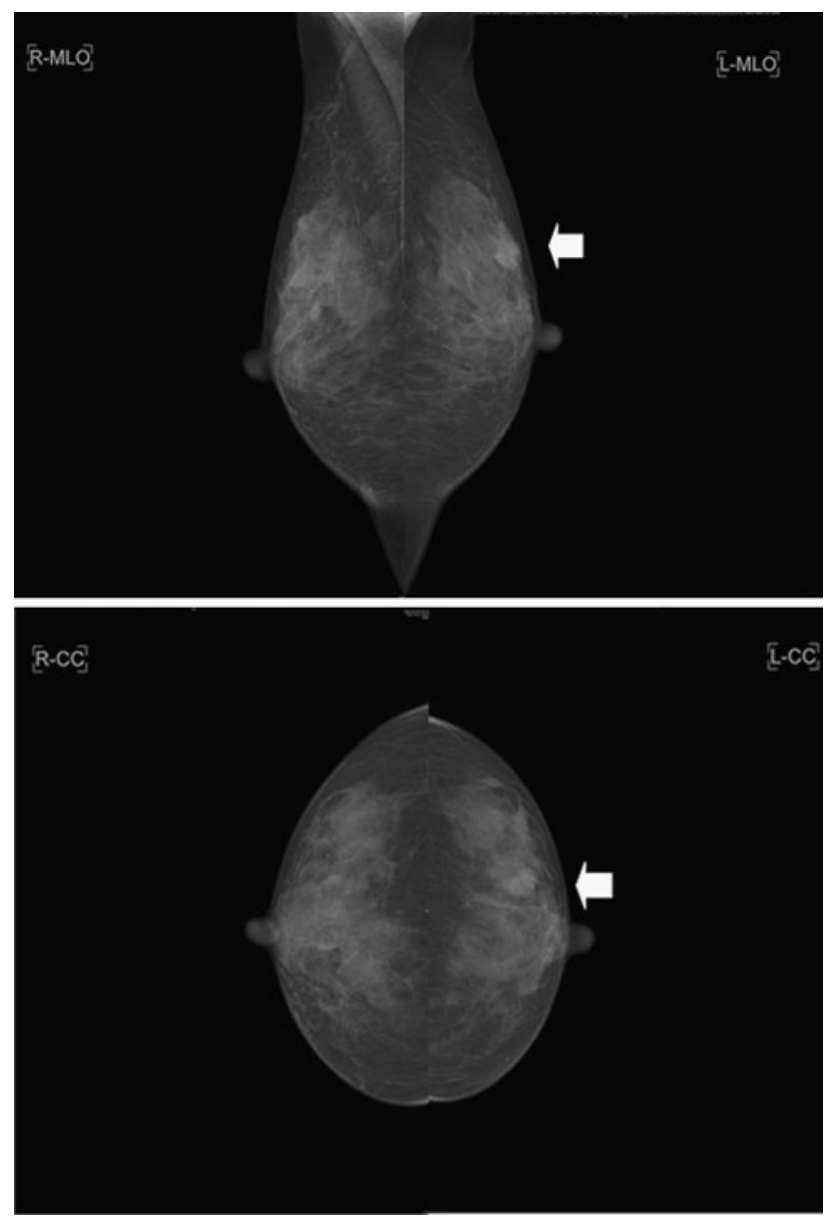

Fig. 2 Mammography: the tumor (arrow) is observed on the left

tissue (Fig. 2). Ultrasonography revealed an oval, circumscribed, homogenous hypoechoic mass with extreme posterior acoustic enhancement. Fine-needle aspiration of the mass was performed under ultrasonographic guidance. The diagnosis was malignant, with presumption of a metastasis of parathyroid carcinoma. Laboratory findings included: serum calcium $8.7 \mathrm{mg} / \mathrm{dl}$ (normal range, $8.7-10.3 \mathrm{mg} / \mathrm{dl}$ ), intact parathyroid hormone (PTH-intact) $41 \mathrm{pg} / \mathrm{ml}$ (normal range, $10-65 \mathrm{pg} / \mathrm{ml}$ ), thyroid-stimulating hormone $5.6 \mu \mathrm{U} /$ $\mathrm{ml}$ (normal range, $0.27-4.2 \mu \mathrm{U} / \mathrm{ml}$ ), and thyroxine $1.5 \mathrm{ng} /$ $\mathrm{dl}$ (normal ranges, $1.0-1.8 \mathrm{ng} / \mathrm{dl}$ ).

A partial resection of the mammary gland including the tumor with a $0.5-\mathrm{cm}$ safety margin was performed under local anesthesia. Grossly, the sectioned specimen revealed a grayish-white, oval tumor measuring $1.1 \mathrm{~cm}$ in diameter, and the cut tumor surface displayed opalescence (Fig. 3). Histological examination of the tumor revealed tumor cells forming atypical solid nests with round to oval nuclei, granular chromatin with occasional small nucleoli, and scant cytoplasm (Fig. 4a, b). Immunohistochemical staining was negative for CEA, thyroglobulin, S-100 protein,

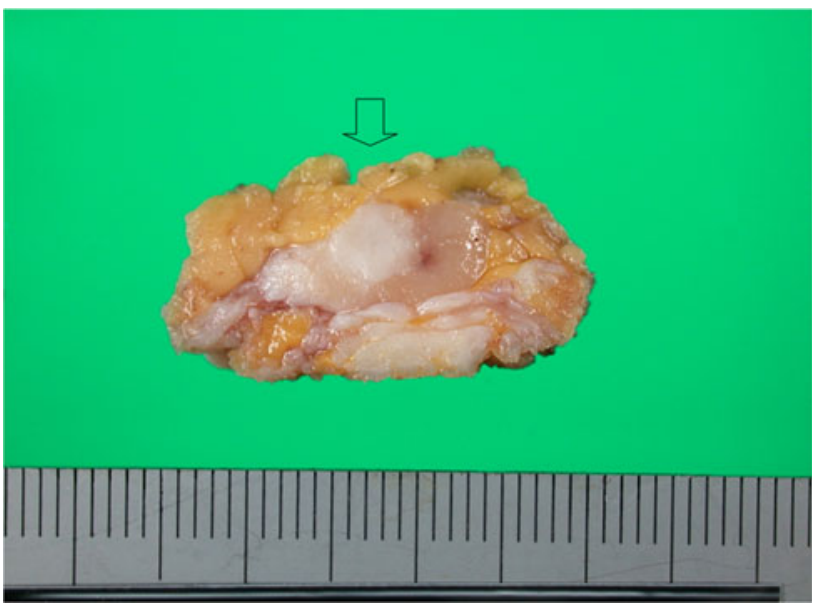

Fig. 3 Gross section of tumor: a white, glossy, and circumscribed nodule is seen (arrow)

EMA, calcitonin, CA19-9, E-cadherin, cytokeratin $34 \beta$ E12 estrogen receptor, progesterone receptor, HER2, and parathyroid hormone (Fig. 4c); and was positive for NSE, synaptophysin (Fig. 5a), chromogranin A (Fig. 5b), and cytokeratin AE1/AE3. Ki-67 of the metastasis showed $10.2 \%$ positivity (Fig. 5c). Based on the light microscopy findings and the immunohistochemical staining profile, the breast tumor was diagnosed as a metastasis of parathyroid carcinoma.

The postoperative serum calcium was $8.8 \mathrm{mg} / \mathrm{dl}$. The patient is now undergoing RT for metastasis to occipital bone around the left hypoglossal canal. She also continues to be followed in our hospital.

\section{Discussion}

Patients with nonfunctional parathyroid carcinomas are usually asymptomatic with normal calcium and PTH levels. Therefore, they are difficult to diagnose clinically, and most patients are diagnosed at an advanced stage of the disease with the initial symptoms being associated with the large size and invasiveness of these tumors. Our patient discovered the mass in her breast. This indicates that in cases with a past history of nonfunctional parathyroid carcinoma, regular self examination to detect metastases to external organs such as the breast is important. In addition, technetium-99m sestamibi and computed tomography (CT) scans and magnetic resonance imaging may be useful for detecting metastases to internal organs. Technetium-99m sestamibi imaging can locate endocrinologically inactive metastases [11]. Busaidy et al. presented a comparative summary of a few published institutional experiences covering 109 patients with parathyroid carcinoma from 

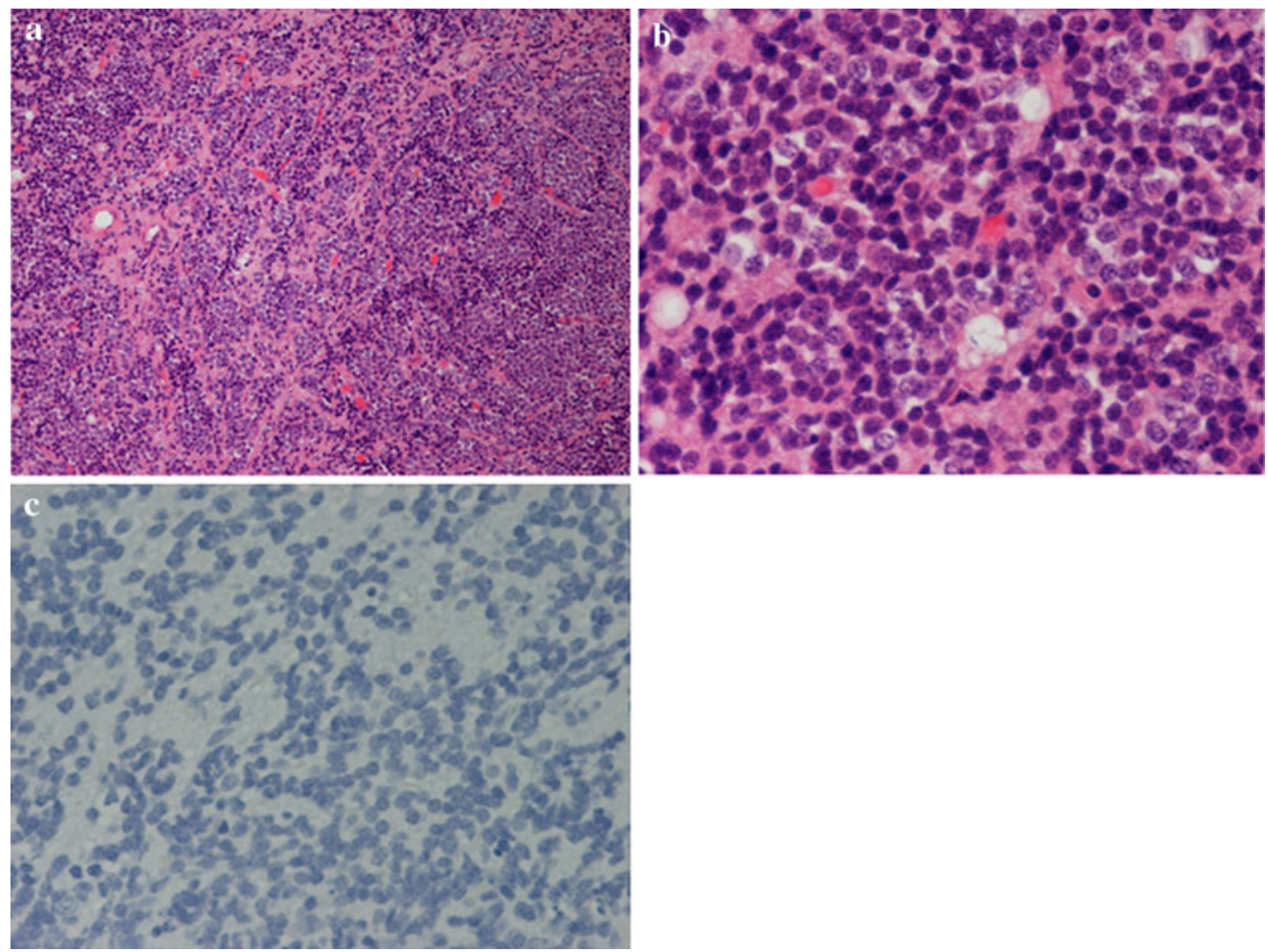

Fig. 4 Histological appearance of breast metastasis of nonfunctional parathyroid carcinoma: a Sheets or lobules of tumor cells are shown [hematoxylin and eosin $(\mathrm{H} \& \mathrm{E})$ stain $\times 100$ ]; b tumor cells showing atypical solid nests with round to oval nuclei, granular chromatin with occasional small nucleoli, and scant cytoplasm $(H \& E$ stain $\times 400)$; $\mathbf{c}$ the cytoplasm of tumor cells is negative for parathyroid hormone
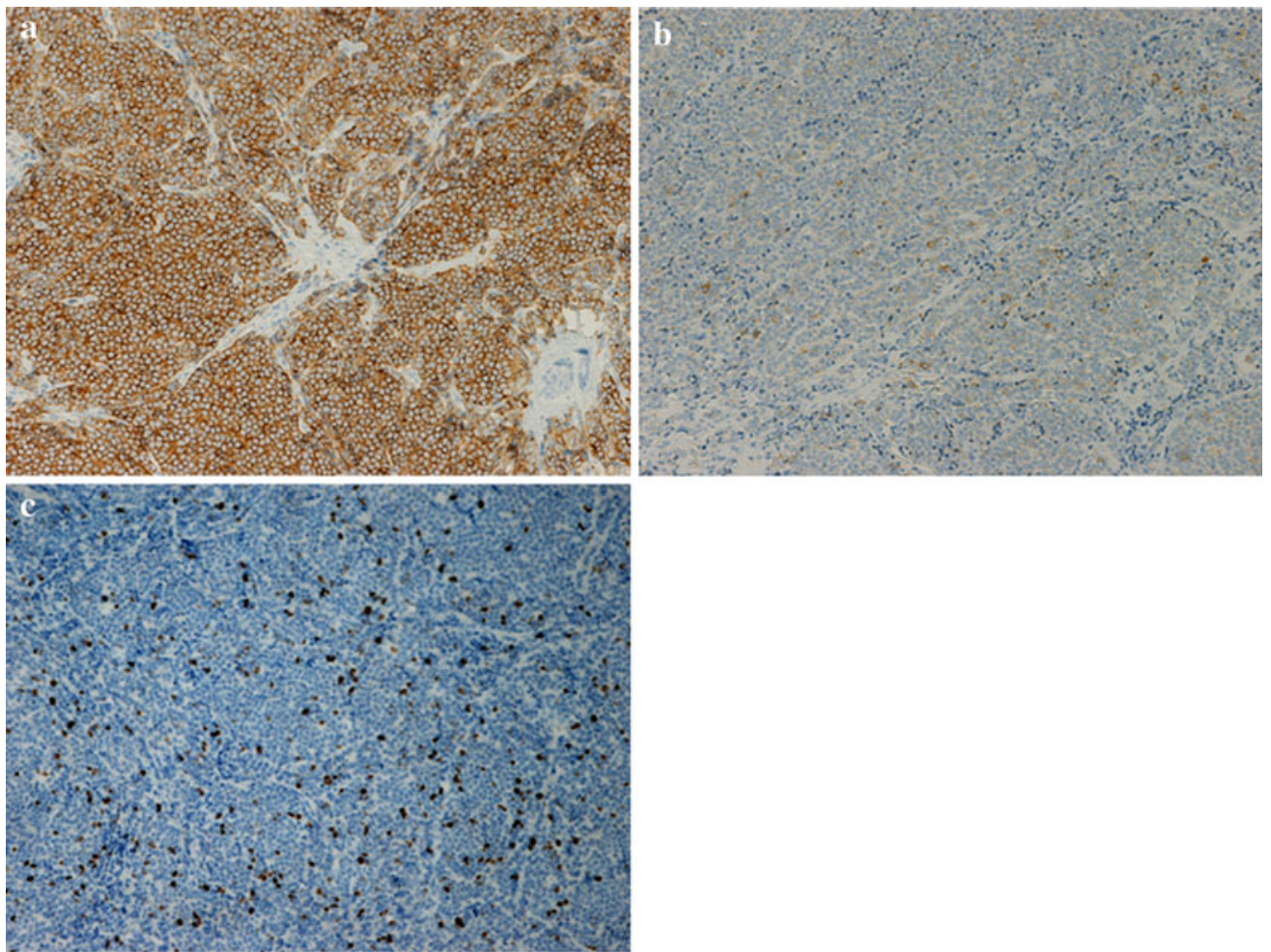

Fig. 5 a Cytoplasm of tumor cells is clearly reactive for synaptophysin expression $(\times 100)$. b Cytoplasm of tumor cells is clearly reactive for chromogranin A expression $(\times 100)$. c Ki-67 reactivity of metastatic tumor $(\times 100)$ 
Table 1 Reported cases of nonfunctional parathyroid carcinoma

$M$ male, $F$ female, $L N$ lymph node, $N M$ not mentioned

\begin{tabular}{|c|c|c|c|}
\hline Reference & Age/sex & Distant metastasis & Survival \\
\hline $\begin{array}{l}\text { Current Study (2011) and } \\
\text { Nakamura et al. (2010) }\end{array}$ & $71 / \mathrm{F}$ & $\begin{array}{l}\text { Breast, cranial bone, } \\
\text { mediastinum }\end{array}$ & Alive at 6 years and 3 months \\
\hline Gao et al. (2009) & $47 / \mathrm{M}$ & None & Alive at 8 months \\
\hline Wilkins and Lewis (2009) & $59 / \mathrm{M}$ & None & Alive at 7 months \\
\hline Grodski et al. (2008) & $46 / \mathrm{M}$ & Lung & NM \\
\hline Fernandez-Ranvier et al. (2007) & $67 / F$ & Lung & Alive at 2 years and 7 months \\
\hline Ashkenazi et al. (2006) & $54 / \mathrm{F}$ & None & Alive at 1 year \\
\hline Kirkby-Bott et al. (2005) & $66 / \mathrm{M}$ & Lung, bone & Dead at 8 years and 2 months \\
\hline Yamashita et al. (1992) & $56 / \mathrm{F}$ & None & Alive at 10 months \\
\hline Klink et al. (1991) & 39/M & None & Alive at 4 months \\
\hline Collins et al. (1986) & $65 / \mathrm{M}$ & None & Alive at 2 years \\
\hline Murphy et al. (1986) & $51 / \mathrm{M}$ & None & Alive at 11 months \\
\hline Baba et al. (1986) & $64 / \mathrm{F}$ & None & Alive at 1 year \\
\hline Merlano et al. (1985) & $59 / \mathrm{M}$ & $\begin{array}{l}\text { Live, axillary and } \\
\text { supraclavicular LN }\end{array}$ & Alive at 4 years \\
\hline Yamashita et al. (1984) & $69 / \mathrm{F}$ & None & Alive at 1 year and 8 months \\
\hline Anderson et al. (1983) & $59 / \mathrm{M}$ & Lung, bone, mediastinum & Dead at 1 year and 8 months \\
\hline Aldinger et al. (1982) & $27 / M$ & Lung, brain, axillary LN & Dead at 2 years \\
\hline Aldinger et al. (1982) & $49 / \mathrm{M}$ & Lung, bone, mediastinum & Alive at 9 months \\
\hline Chahinian et al. (1981) & $69 / \mathrm{F}$ & Lung & Alive at 8 years \\
\hline Dhom et al. (1980) & $38 / \mathrm{M}$ & NM & NM \\
\hline Altenähr et al. (1973) & $50 / \mathrm{M}$ & None & Alive at 7 years \\
\hline Pachter et al. (1963) & $50 / \mathrm{F}$ & Supraclavicular LN, skin & Alive at 5 years \\
\hline Sieracki et al. (1960) & $43 / \mathrm{F}$ & None & Alive at 3 years \\
\hline McQuillan (1938) & $53 / \mathrm{F}$ & None & Alive at 2 year and 4 months \\
\hline Armstrong (1938) & $71 / \mathrm{F}$ & None & Alive at 2 months \\
\hline Guy (1926) & $29 / \mathrm{F}$ & Lung & Alive at 2 years and 4 months \\
\hline
\end{tabular}

stomach cancers [14]. A parathyroid carcinoma metastatic to the mammary gland has never been reported.

The characteristic mammographic and ultrasonographic findings of breast metastasis from parathyroid carcinomas have not been previously reported, although these imaging modalities are widely used to detect breast cancers. The breast mass of our patient appeared as a circumscribed mass on mammography and ultrasonography. The abundance of homogenous tumor cells resulted in homogenous hypoechoic tumor with extreme posterior acoustic enhancement. These findings suggest that metastasis of parathyroid carcinoma should be included in the differential diagnosis when a hypoechoic and homogenous tumor with enhanced posterior echo is seen in the breast of a patient with a past history of parathyroid carcinoma.

The differential diagnosis includes primary breast neuroendocrine carcinoma. Specific finding of primary breast neuroendocrine carcinoma, compared with metastatic breast neuroendocrine carcinoma, has not been reported. However, the primary lesion usually has intraductal component. Because the finding was not seen in our patient, primary neuroendocrine carcinoma of the breast is unlikely. 
Knowledge of prognostic factors in parathyroid carcinoma is limited. $\mathrm{Ki}-67$ is reported to be a valuable prognostic factor for patients with parathyroid carcinoma, and aggressive surgical resection at the initial surgery is reported to lead to better outcomes [16]. In our patient, the Ki-67 labeling index was slightly increased in the metastatic tumor $(10.2 \%)$ compared with the primary $(7.9 \%)$. This suggests that tumor cells with higher proliferative activity may be associated with recurrence and/or metastasis.

In conclusion, we have described the first case of a breast metastasis from parathyroid carcinoma. Physical examination, mammography, and ultrasonography were useful in detecting parathyroid carcinoma metastasis in the breast. Breast metastasis of parathyroid carcinoma should be included in the differential diagnosis for a patient with a past history of parathyroid carcinoma.

Conflict of interest None.

\section{References}

1. Fujita T (1983) Primary hyperparathyroidism. Nippon Rinsho 41(supplement):823-830

2. Schantz A, Castleman B (1973) Parathyroid carcinoma: a study of 70 cases. Cancer 31:600-605

3. Sandelin K, Auer G, Bondeson L et al (1992) Prognostic factors in parathyroid cancer: a review of 95 cases. World J Surg $16: 724-731$
4. Obara T, Fujimoto Y (1991) Diagnosis and treatment of patients with parathyroid carcinoma: an update and review. World J Surg 15:738-744

5. Sandelin K, Tullgren O, Farnebo LO (1994) Clinical course of metastatic parathyroid cancer. World J Surg 18:594-599

6. Cordeiro AC, Montenegro FL, Kulcsar MA et al (1998) Parathyroid carcinoma. Am J Surg 175:52-55

7. Hundahl SA, Fleming ID, Fremgen AM et al (1999) Two hundred eighty-six cases of parathyroid carcinoma treated in the U.S. between 1985-1995: a National Cancer Data Base Report. The American College of Surgeons Commission on Cancer and the American Cancer Society. Cancer 86:538-544

8. Busaidy NL, Jimenez C, Habra MA et al (2004) Parathyroid carcinoma: a 22-year experience. Head Neck 26:716-726

9. Wilkins BJ, Lewis JS Jr (2009) Non-functional parathyroid carcinoma: a review of the literature and report of a case requiring extensive surgery. Head Neck Pathol 3:140-149

10. Nakamura Y, Kataoka H, Sakoda T et al (2010) Nonfunctional parathyroid carcinoma. Int J Clin Oncol 15:500-503

11. Ashkenazi D, Elmalah I, Rakover Y (2006) Concurrent nonfunctioning parathyroid carcinoma and parathyroid adenoma. Am J Otolaryngol 27:204-206

12. Gao WC, Ruan CP, Zhang JC et al (2010) Nonfunctional parathyroid carcinoma. J Cancer Res Clin Oncol 136:969-974

13. Busaidy NL, Jimenez C, Habra MA et al (2004) Parathyroid carcinoma: a 22-year experience. Head Neck 26:716-726

14. Nielsen M, Andersen JA, Henriksen FW et al (1981) Metastases to the breast from extramammary carcinomas. Acta Pathol Microbiol Scand A 89:251-256

15. Toombs BD, Kalisher L (1977) Metastatic disease to the breast: clinical, pathologic, and radiographic features. AJR Am J Roentgenol 129:673-676

16. Iihara M, Okamoto T, Suzuki R et al (2007) Functional parathyroid carcinoma: long-term treatment outcome and risk factor analysis. Surgery 142:936-943 